\title{
Mechanical and Pressure-Sensitive Properties of Cement Mortar Containing $\mathrm{Nano}-\mathrm{Fe}_{2} \mathrm{O}_{3}$
}

\author{
Yiqin $\mathrm{FANG}^{1}$, Yaru $\mathrm{SUN}^{2}$, Meiyuan $\mathrm{LU}^{3}$, Feng $\mathrm{XING}^{4}$, Weiwen LI* \\ School of Civil Engineering, Guangdong Province \\ Key Laboratory of Durability for Marine Civil Engineering, Shenzhen University \\ Shenzhen, China \\ e-mail: 601514810@qq.com; yaru.sun@mail.polimi.it; 792089640@qq.com; xingf@ szu.edu.cn; liweiwen@ szu.edu.cn
}

\begin{abstract}
The mechanical and pressure-sensitive properties of nano- $\mathrm{Fe}_{2} \mathrm{O}_{3}$ cement paste were experimentally studied. The experimental results showed that, except at the 7-day age, the compressive strength of cement paste doped with different amounts of nano- $\mathrm{Fe}_{2} \mathrm{O}_{3}$ measured at the 14-day and 28-day ages had a steady increase compared with the control group. All peak values of intensity appeared in adding amounts of nano- $\mathrm{Fe}_{2} \mathrm{O}_{3}$ with $10 \%$. However, the increase of compressive strength at the 28-day age was less than those found at the 7-day and 14-day ages. The pressure-sensitivity was also progressively improved with the increase of adding amount of nano- $\mathrm{Fe}_{2} \mathrm{O}_{3}$, though the escalating trend leveled out when the adding amount of nano- $\mathrm{Fe}_{2} \mathrm{O}_{3}$ was more than $5 \%$. It is proposed that the improvement of compressive strength and pressure-sensitivity of cement paste with doped nano- $\mathrm{Fe}_{2} \mathrm{O}_{3}$ is attributed to the reason that nano- $\mathrm{Fe}_{2} \mathrm{O}_{3}$ fills the pores in the hydration product and accelerates overall hydration. Moreover, according to Scanning Electron Microscope (SEM) and $\mathrm{X}$-Ray Diffraction (XRD) results, nano- $\mathrm{Fe}_{2} \mathrm{O}_{3}$ may react with $\mathrm{Ca}(\mathrm{OH})_{2}$ and produce additional $\mathrm{C}-\mathrm{S}-\mathrm{H}$ gel. The pozzolanic reaction has occurred. Thus, the compressive strength of cement paste doped with nano- $\mathrm{Fe}_{2} \mathrm{O}_{3}$ is increased. Meanwhile, the magnetism of nano- $\mathrm{Fe}_{2} \mathrm{O}_{3}$ is also the reason for the improvement in the pressure-sensitivity of cement paste.
\end{abstract}

Keywords-Nano- $\mathrm{Fe}_{2} \mathrm{O}_{3}$; cement mortar; mechanical property; pressure-sensitive property ; functional material

\section{INTRODUCTION}

Nanotechnology deals with microstructures or micro-sized materials. Scientists reported that nanoparticles can improve the smart materials which develops properties such as durability, mechanical performance, thermal, electrical and conductivity insulation, etc. Li et al. [1-2] found that cement mortar added with nano-Fe2O3 could improve the pressure-sensitive performance of mortar, which could be used to monitor the pressure change of cement-based material. The experimental results showed that the self diagnostic ability improved with the adding amount of nano- $\mathrm{Fe}_{2} \mathrm{O}_{3}$. The above investigations indicate that maybe the cement mortar containing with nano- $\mathrm{Fe}_{2} \mathrm{O}_{3}$ is an excellent functional material for monitoring pressure change of cement-based materials.

In previous research, most of investigations of nano-Fe2O3 on the property of cement-based materials were primarily limited to the mechanical performances. It was found in the study by Khoshakhlagh et al. [3] that the compressive strength with adding amount of $4 \%$ was the highest at the 28-day. $\mathrm{Nano}-\mathrm{Fe}_{2} \mathrm{O}_{3}$ could accelerate the formation of $\mathrm{C}-\mathrm{S}-\mathrm{H}$ gel. This phenomenon was especially obvious in the early hydration process. Therefore, the strength of specimen was improved by the addition of nano- $\mathrm{Fe}_{2} \mathrm{O}_{3}$. It helps to compare the reinforcing mechanism in compressive strength using other nano-materials in previous research such as carbon nanotubes (CNTs) [4]. The investigation by Yazdi et al. [5] also support the above results. Yazdi et al. proposed that, when the adding amount of $5 \%$ nano- $\mathrm{Fe}_{2} \mathrm{O}_{3}$, the distance of nanoparticles became smaller so that the $\mathrm{Ca}(\mathrm{OH})_{2}$ crystal did not have enough space to grow to a favorable size and reduced the compressive strength.

$\mathrm{Li}$ et al. [1] investigated the change of $\Delta \mathrm{R} / \mathrm{R} 0$ ( $\mathrm{R} 0$ and $\Delta \mathrm{R}$ are respectively defined as the resistance of specimen before loading and the difference of resistance between the resistance of specimen after loading and R0) for cement mortar with adding amounts of $3 \%$ and $5 \%$ nano- $\mathrm{Fe}_{2} \mathrm{O}_{3}$ with increasing gradually pressure until the ultimate load. The experimental results showed that the experimental group with the adding amount of $5 \%$ was more sensitive than that of the $3 \%$ adding amount. Furthermore, it was concluded that the longitudinal fracture had no influence on the resistance of specimen during the process of pressure increase for specimen until it broke. Additionally, two reasons why the resistance decreased during the process of pressure increase were also proposed. The energy gap of nano-particles was reduced during the process of pressure increase for the fact that nano- $\mathrm{Fe}_{2} \mathrm{O}_{3}$ acted a kind of semiconductor material that could absorb energy. Thus, it was easier to transfer the electrons of the nano-particles, improving electrical conductivity. Moreover, during the process of pressure increase, nano-particles became closer to one another with the increase of pressure. Therefore, the tunneling current was more intense and the resistance of specimen also decreased. Sanchez et al. [6] concluded that both the mechanical performance and the sense performance of self pressure change were improved after nano- $\mathrm{Fe}_{2} \mathrm{O}_{3}$ was added into cement mortar. Furthermore, it was proposed that such sense performance could be useful in the real-time health monitoring of the structure and construction of intelligent building. 


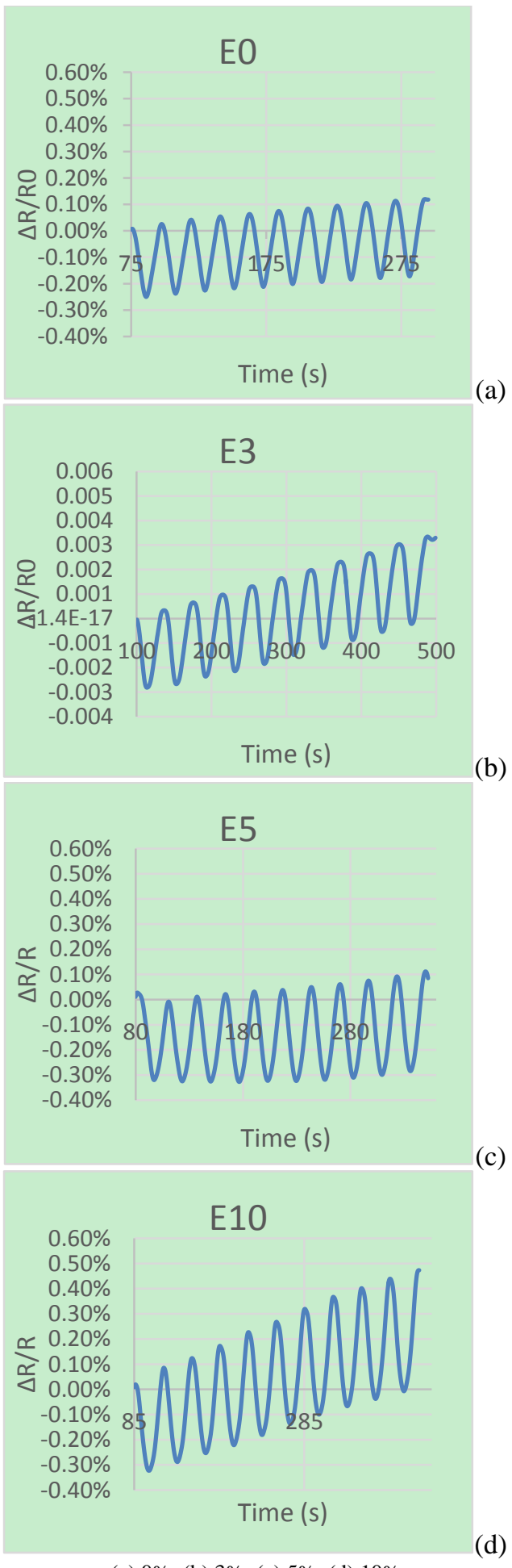

(a) $0 \%$; (b) $3 \%$; (c) $5 \%$; (d) $10 \%$.

Figure 1. The resistance image of cement mortars with different additions of nano-Fe2O3 at:

Based on the above understanding, the pressure-sensitive properties of cement mortar containing different amounts of nano- $\mathrm{Fe}_{2} \mathrm{O}_{3}$ is the major investigation target to observe the results of experiment and analyze the phenomenon with the comparison.

\section{EXPERIMENTAL DESIGN}

The mortar with different adding amount of nano- $\mathrm{Fe}_{2} \mathrm{O}_{3}$ with a w/c ratio of 0.5 varied respectively from $0,3,5$ and $10 \%$. The resulting paste was then poured into molds with dimensions of $40 \mathrm{~mm} \times 40 \mathrm{~mm} \times 160 \mathrm{~mm}$, which were removed from the mold after 24 hours and cured in water at $20{ }^{\circ} \mathrm{C}$ until the testing age. After curing for designed curing time (7-day, 14-day, 28-day), the cement cube axial compressive test (guaranteed by Chinese national standard GBT 17671-1999) was proceeded to measure compressive strength for 6 specimens to record the compressive strength. The 28-day age specimen would be dried for 24 hours at 70 ${ }^{\circ} \mathrm{C}$ to measure the change of electrical resistance by cyclic loading at 10 times for its $15 \%$ of ultimate loading force. The fragment of mechanical test would be sent to the Scanning Electron Microscope (SEM) and X-Ray Diffraction (XRD) tests.

\section{RESULTS AND ANALYSIS}

\section{A. Results on Mechanical Property Test}

In the test of compressive properties, the compressive strength has been tested at the 7-day, 14-day, and 28-day age, respectively. The results are shown in Table 1 , where it can be seen that with increasing adding amounts of nano-Fe2O3, the compressive strength exhibits a trend of gradual increase at the 7-day, 14-day, and 28-day ages. Although the compressive strength at the 7-day age increases with the increasing adding amount of nano- $\mathrm{Fe}_{2} \mathrm{O}_{3}$, the compressive strength is essentially the same with that with the $3 \%$ adding amount when the adding amount reaches $5 \%$. The peak value of strength for all the ages appears in A10 group with the adding amount of $10 \%$, which is increased by $66.81 \%$, $69.76 \%$, and $25.20 \%$, respectively. Furthermore, when the adding amount increases from $5 \%$ to $10 \%$, there is a significant increase, which is approximately the same as the strength increase trend of Khoshakhlagh [3] and Nazari [7]. It can be observed that nano-Fe2O3 has a greater impact on the early strength of cement. In the later period, with the increase of adding amount, the increase of its compressive strength tends to gradually become mild relative to the 7-day and 14-day ages, where no leaping increase occurs again. In the same curing age, the compressive strength of specimen changes with the increase of adding amount of nano- $\mathrm{Fe}_{2} \mathrm{O}_{3}$. It can be seen that the biggest rising range of compressive strength of specimen happened at the 14-day age, and the compressive strength of specimen with a adding amount of $10 \%$ is almost the same as that of the 28-day age. It can be speculated that nano- $\mathrm{Fe}_{2} \mathrm{O}_{3}$ promotes the early hydration reaction of cement. Therefore, the compressive strength of A10 group with the largest adding amount of nano- $\mathrm{Fe}_{2} \mathrm{O}_{3}$ has a leaping increase at the 7-day and 14-day ages. Its impact on the hydration of cement in the later period gradually decreases; thus, the increase of compressive strengthening tends to gradually mild at the 28-day age. 
TABLE I. COMPRESSive StREngth Of CEMENT Mortars With DifFERENT AdDitions OF NANO-FE $\mathrm{O}_{3}$

\begin{tabular}{c|c|c|c|c|c|c}
\hline \multirow{2}{*}{ Dosage } & \multicolumn{2}{|c|}{7 day } & \multicolumn{2}{c|}{14 day } & \multicolumn{2}{c}{28 day } \\
\cline { 2 - 7 } & $\begin{array}{c}\text { Strength } \\
(\mathrm{MPa})\end{array}$ & $\begin{array}{c}\text { Rising } \\
\text { percentage }\end{array}$ & $\begin{array}{c}\text { Strength } \\
(\mathrm{MPa})\end{array}$ & $\begin{array}{c}\text { Rising } \\
\text { percentage }\end{array}$ & $\begin{array}{c}\text { Strength } \\
(\mathrm{MPa})\end{array}$ & $\begin{array}{c}\text { Rising } \\
\text { percentage }\end{array}$ \\
\hline $0 \%$ & 18.86 & - & 23.08 & - & 33.02 & - \\
\hline $3 \%$ & 24.65 & $30.70 \%$ & 25.58 & $10.83 \%$ & 38.50 & $16.60 \%$ \\
\hline $5 \%$ & 23.60 & $25.13 \%$ & 27.14 & $17.59 \%$ & 39.08 & $18.35 \%$ \\
\hline $10 \%$ & 31.46 & $66.81 \%$ & 39.18 & $69.76 \%$ & 41.34 & $25.20 \%$ \\
\hline
\end{tabular}

\section{B. Results on Pressure-Sensitive Property Test}

In the pressure-sensitivity property testing, the relative change rate of resistance also shows a linear increase and negative pressure-sensitive property with the increase of loading force [8]. In Figure 1, it can be seen that, with the increase of adding amount of nano- $\mathrm{Fe}_{2} \mathrm{O}_{3}$, the relative change rate of $\Delta \mathrm{R} / \mathrm{R} 0$ of the resistance of specimen gradually increases, which gradually increases from $0.22 \%$ of control group to $0.32 \%$. The highest increase reaches $39.1 \%$. However, when the adding amount reaches $5 \%$, the relative change rate of resistance gradually stabilizes at $0.32 \%$, and no large increase appears. It can be speculated that when the adding amount reaches $5 \%$, the influence of nano- $\mathrm{Fe}_{2} \mathrm{O}_{3}$ on the sensitivity of cement reaches its limit value. An increase in the adding amount of nano- $\mathrm{Fe}_{2} \mathrm{O}_{3}$ would not be able to generate a heightened influence on the pressure-sensitive property - when the addition of nano- $\mathrm{Fe}_{2} \mathrm{O}_{3}$ is too much, the internal stability of the cement structure is affected. This may be attributed to the excess of nano- $\mathrm{Fe}_{2} \mathrm{O}_{3}$, which exceeds the required amount of reaction with the free-form line. Nano- $\mathrm{Fe}_{2} \mathrm{O}_{3}$ replaces part of the cementation material. Therefore, with the increase in the number of cycles, the number of micro-fracture appearing in the specimen sharply increases. At the same time, the internal structure is damaged. As a result, the resistance can no longer return to its original value and a great increase appears, generating an unfavorable impact for the experimental study.

With an increase in the adding amount of nano- $\mathrm{Fe}_{2} \mathrm{O}_{3}$, the appearance of phenomenon that the relative change rate of resistance increases is mainly attributable to the following reasons. First, the pores in the cement structure are filled with nano- $\mathrm{Fe}_{2} \mathrm{O}_{3}$ as a filling material. The distance of cement particles and cement products decreases, thus improving electrical conductivity. Furthermore, nano- $\mathrm{Fe}_{2} \mathrm{O}_{3}$ has good magnetic properties and can be easily oriented. With the gradual increase of subjected load of specimen, the distance of nano- $\mathrm{Fe}_{2} \mathrm{O}_{3}$ particles gradually decreases. These particles are steadily arranged because of the magnetic effect. Therefore, the conductive path is formed and the resistance decreases. As a result of these characteristics of nano- $\mathrm{Fe}_{2} \mathrm{O}_{3}$, the rate of resistance change of specimen is accelerated in the compression process, improving the pressure-sensitive property of cement.

\section{Analysis on SEM and XRD Images}

By comparing SEM images of control group in Figure 2(a), it is found that some conglobate materials appear in
Figure 2(b) when the adding amount of nano- $\mathrm{Fe}_{2} \mathrm{O}_{3}$ is $3 \%$. It can be speculated that these materials are the aggregated nano- $\mathrm{Fe}_{2} \mathrm{O}_{3}$. When the adding amount increases to $5 \%$, it can be observed that the surface morphology and quantity of acicular ettringite change becoming denser. This is owing to the fact that nano- $\mathrm{Fe}_{2} \mathrm{O}_{3}$ promotes the early hydration and acts as an external nucleation to promote the generation of C-S-H gel [7,9], ultimately improving the strength. Simultaneously, the pores of cement pastes are better-filled. When the adding amount of nano- $\mathrm{Fe} 2 \mathrm{O} 3$ reaches $10 \%$, it can be seen that a large amount of filamentous materials appears, as shown in Figure 2(d). The hydration product is covered by filamentous materials, which lap over each other in the gap. Furthermore, the bridging micro-sized effect is generated while the pores are filled by nano-Fe2O3, similar to the phenomenon as other nano-materials $[10,11]$. The compressive strength of the specimen is also further increased because the generation of fracture is controlled when the specimen is affected by pressure. Concurrently, its electrical conductivity is also improved by the bridging effect of these materials. From SEM results from samples of each group, it is concluded that nano- $\mathrm{Fe} 2 \mathrm{O} 3$ acts a filling role in cement, increasing the compactness of cement, and also increasing the compressive strength. Khoshakhlagh et al. [3] have also proved this statement.

It can be seen from the XRD images in Figure 3 that, compared with the control group of $0 \%$, there is a significant decrease of the content of $\mathrm{Ca}(\mathrm{OH})_{2}$ produced from cement hydration. It can be speculated that nano- $\mathrm{Fe}_{2} \mathrm{O}_{3}$ is involved in the hydration reaction. The possible reason for the significant decrease of the $\mathrm{Ca}(\mathrm{OH})_{2}$ content is the pozzolanic reaction between nano- $\mathrm{Fe}_{2} \mathrm{O}_{3}$ and $\mathrm{Ca}(\mathrm{OH})_{2}$. The so-called pozzolanic reaction refers to the reaction between the active substance in cement and $\mathrm{Ca}(\mathrm{OH})_{2}$, which generates hydrated calcium silicate, hydrated calcium aluminate, or hydrated calcium sulfoaluminate, as well as other hydration products. Nano- $-\mathrm{Fe}_{2} \mathrm{O}_{3}$ is likely to act as the active substance in the hydration of cement and react with $\mathrm{Ca}(\mathrm{OH})_{2}$, thereby consuming the rapidly-formed $\mathrm{Ca}(\mathrm{OH})_{2}$ upon hydration effect and generating the C-S-H gel. Since abundant $\mathrm{Ca}(\mathrm{OH})_{2}$ is produced in the early hydration reaction of cement, nano- $\mathrm{Fe}_{2} \mathrm{O}_{3}$ is also involved in a large portion of hydration reaction during this period. Therefore, the compactness of cement is improved and its compressive strength is also significantly increased in the early hydration of cement. 


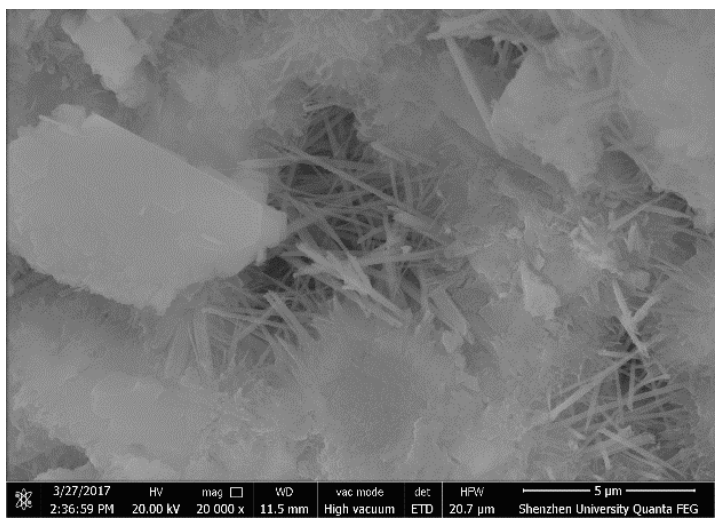

(a)

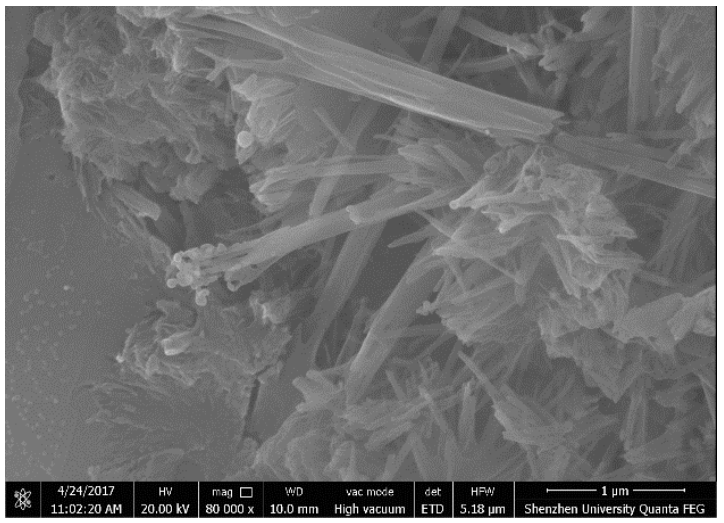

(c)

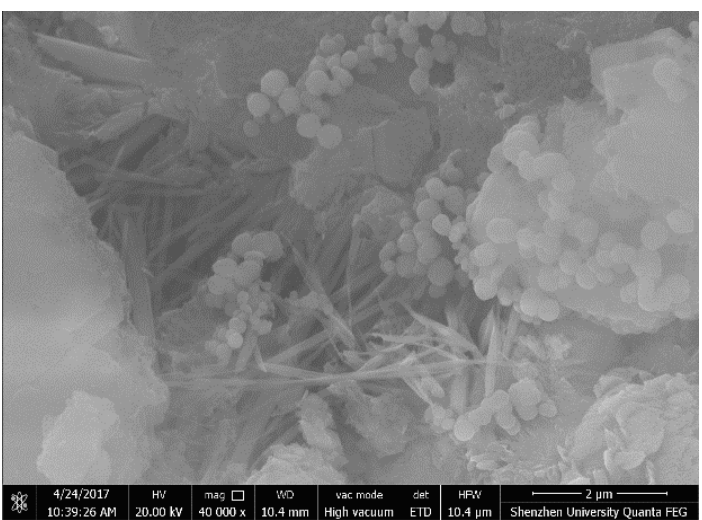

(b)

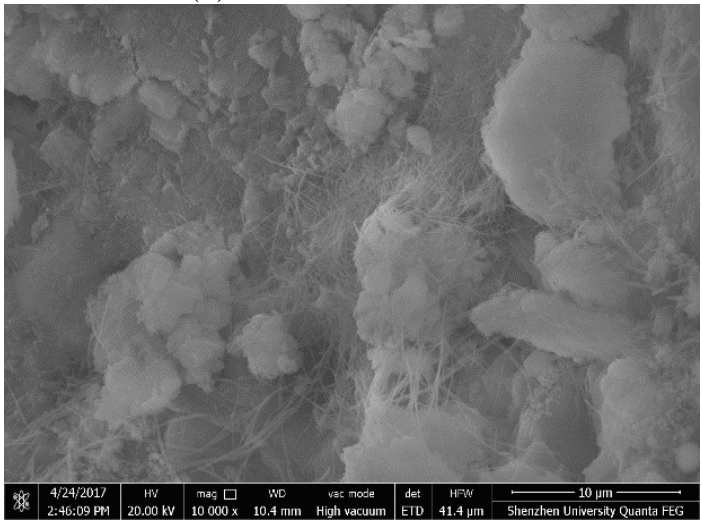

(d)

Figure 2. Typical SEM image of specimens with different additions of nano- $\mathrm{Fe}_{2} \mathrm{O}_{3}$ (a) $0 \%$; (b) $3 \%$; (c) $5 \%$; (d) $10 \%$.

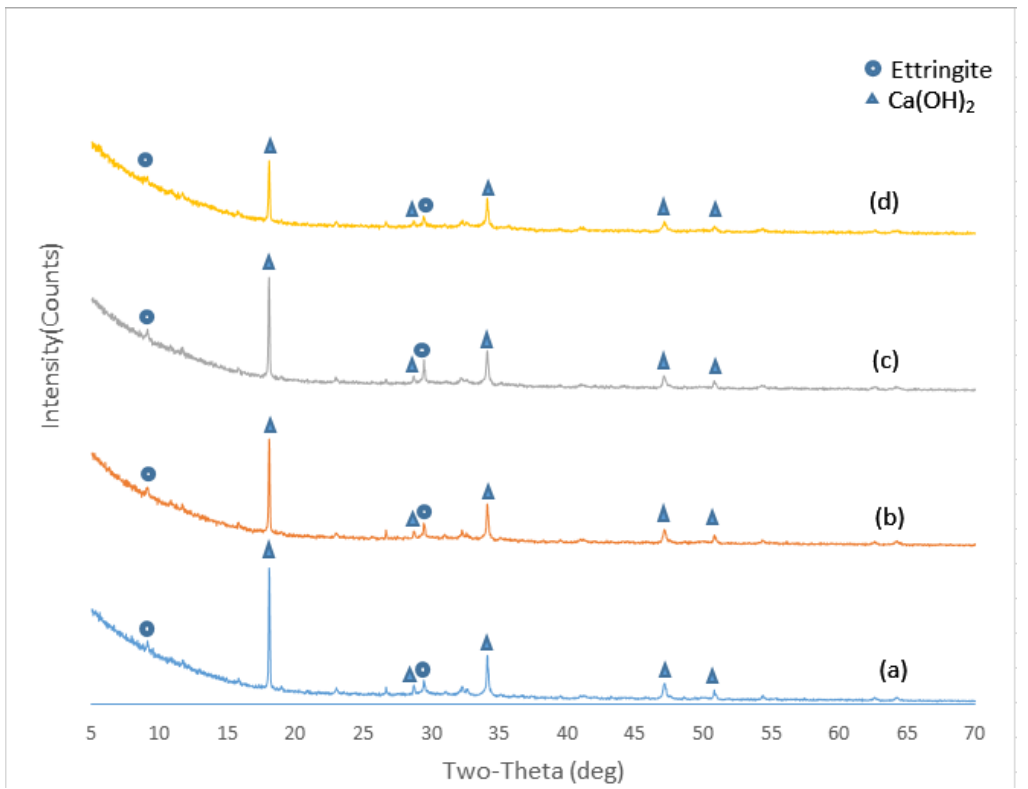

Figure 3. The XRD images of 28-day age specimens with different additions of nano-Fe2O3 (a) $0 \%$, (b) $3 \%$, (c) $5 \%$, (d) $10 \%$. 


\section{CONCLUSIONS}

The paper focuses on the mechanical and pressure-sensitive properties of cement paste with nano- $\mathrm{Fe}_{2} \mathrm{O}_{3}$. The following conclusions can be drawn from this experimental:

- The compressive strength of cement paste was gradually increased with the increasing adding amount of nano- $\mathrm{Fe}_{2} \mathrm{O}_{3}$, it accelerates the hydration of cement to increase the early compressive strength effectively. In the later period, the increase of its compressive strength gradually tends to be gentle, and no leaping increase appears again.

- The adding amount of nano- $\mathrm{Fe}_{2} \mathrm{O}_{3}$ improve pressure-sensitive properties of cement paste, its filling effect and magnetic property increases the change rate of resistance with same cyclic loading. But the adding amount reaches $5 \%$, the influence of nano- $\mathrm{Fe}_{2} \mathrm{O}_{3}$ on the sensitivity of cement reaches peak value. The more adding amount of nano- $\mathrm{Fe}_{2} \mathrm{O}_{3}$ could not generate more influence on its pressure-sensitive performance.

- Nano- $\mathrm{Fe}_{2} \mathrm{O}_{3}$ is likely to act as the active substance in the hydration of cement and react with $\mathrm{Ca}(\mathrm{OH})_{2}$, consuming the rapid formed $\mathrm{Ca}(\mathrm{OH})_{2}$ upon hydration effect and generating C-S-H gel and ettringite. It helps to make internal structure become more densely to enhance the compressive strength and improve pressure-sensitive property.

\section{ACKNOWLEDGMENT}

The authors would like to gratefully acknowledge Guangdong province science and technology plan projects (Project No. 2015A010105029) and the Shenzhen Strategic Emerging Industry Development Special Fund (No.
JCYJ20150625102603853) for financial support on this study.

\section{REFERENCES}

[1] H. Li, H. Xiao, J. Ou, "A study on mechanical and pressure sensitive properties of cement mortar with nanophase materials," Cement and Concrete Research, Vol. 34, No. 3, 2004, pp.435-438.

[2] H. Li, H. Xiao, J. Yuan, J. Ou, icrostructure of cement mortar with nano-particles, " Composites: Part B Engineering, Vol. 35, No.2, 2004, pp.185-189.

[3] A. Khoshakhlagh, A. Nazari, G. Khalaj, "Effects of $\mathrm{Fe}_{2} \mathrm{O}_{3}$ Nanoparticles on Water Permeability and Strength Assessments of High Strength Self-Compacting Concrete, " Journal of Materials Science and Technology, Vol. 28, No.1, 2012, pp.73-82.

[4] W. Li, W. Ji, Y. Wang, Y. Liu, R. Shen, F. Xing, "Investigation on the mechanical properties of a cement-based material containing carbon nanotube under drying and freeze-thaw conditions, " Materials, Vol. 8, 2015, pp.8780-8792.

[5] N.A. Yazdi, M.R. Arefi, E. Mollaahmadi, B.A. Nejand, "To study the effect of adding $\mathrm{Fe}_{2} \mathrm{O}_{3}$ nanoparticles on the morphology properties and microstructure of cement mortor, " Life Science Journal, Vol 8 , No.4, 2011, pp.550-554.

[6] F. Sanchez, K. Sobolev, "Nanotechnology in concrete-A review, " Construction and Building Materials, Vol. 24, No. 11, 2010, pp.2060-2071.

[7] A. Nazari, S. Riahi, S. Riahi, S.F. Shamekhi, A. Khademno, "Benefits of $\mathrm{Fe}_{2} \mathrm{O}_{3}$ nanoparticles in concrete mixing matrix, " Amecican Journal of Science, Vol. 6, No. 6, 2010, pp.102-106.

[8] M. Hussain, Y.H. Choa, K. Niihara, "Fabrication process and electrical behavior of novel pressure-sensitive composites," Composites: Part A, Vol. 32, No. 12, 2001, pp.1696- 1698.

[9] X. Wang, Y. Yin, Y. Zhou, Y. Hou, "Analysis on toughening mechanisms of ceramic nano-composites, " Journal of Ceramics, Vol.2, 2000, pp.107 - 111

[10] G. Li, P. Wang, X. Zhao, "Mechanical behavior and microstructure of cement composites incorporating surface-treated multi-walled carbon nanotubes, " Carbon, Vol.43, No.6, 2005, pp.1239-1245.

[11] B. Han, X. Yu, J. Ou, "Multifunctional and smart carbon nanotube reinforced cement-based materials," Nanotechnology in civil infrastructure, Springer Berlin Heidelberg, 2011, pp.1-47. 